\title{
Detecção de DNA de Brucella spp. em amostras de sangue e de suabe vaginal ou prepucial de cães do município de Natal, Rio Grande do Norte, Brasil
}

\author{
Detection of Brucella spp. DNA in samples of blood and vaginal or preputial swab \\ from dogs in the county of Natal, Rio Grande do Norte, Brazil \\ Annielle Regina da Fonsêca FERNANDES'; Pomy de Cássia Peixoto KIM²; \\ Sabrina Barros de Araújo DANTAS ${ }^{1}$; Rinaldo Aparecido MOTA²; Sérgio Santos AZEVEDO ${ }^{1}$ \\ ${ }^{1}$ Unidade Acadêmica de Medicina Veterinária do Centro de Saúde e Tecnologia Rural, \\ Universidade Federal de Campina Grande, Patos - PB, Brasil \\ ${ }^{2}$ Departamento de Medicina Veterinária, Universidade Federal Rural de Pernambuco, Recife - PE, Brasil
}

\begin{abstract}
Resumo
Objetivou-se com este trabalho detectar o DNA de Brucella spp. em amostras de sangue e de suabe vaginal ou prepucial de 80 cães sorologicamente positivos para brucelose pela prova de imunodifusão em gel de ágar (IDGA), no município de Natal, estado do Rio Grande do Norte, Brasil. Amostras de sangue total foram colhidas com anticoagulante (citrato de sódio) juntamente com amostras de suabe vaginal e prepucial, para extração de DNA e posterior realização da reação em cadeia da polimerase (PCR) empregando-se os primers ITS66 e ITS279. O DNA de Brucella spp. foi amplificado em seis animais, sendo um animal em ambas as amostras, dois cães em amostras de sangue e três em amostras de suabe do trato reprodutivo. Concluiu-se que a infecção por Brucella spp. está presente em cães no município de Natal, e que a deteç̧ão de DNA do agente em amostras de suabe do trato reprodutivo podem ser utilizadas como ferramenta suplementar no diagnóstico de brucelose canina.
\end{abstract}

Palavras-chave: Brucelose. Cães. PCR. Sangue. Suabe vaginal. Suabe prepucial.

\begin{abstract}
The aim of this work was to detect Brucella spp. DNA in samples of blood and vaginal or preputial swabs in 80 seropositive dogs for brucellosis by agar gel immunodiffusion test (AGID) from the county of Natal, Rio Grande do Norte State, Brazil. Whole blood samples were collected with anticoagulant (sodium citrate) and vaginal and preputial swab samples for DNA extraction and polymerase chain reaction (PCR) employing ITS66 and ITS279 primers. Six animals showed amplification of Brucella spp., being one animal in both samples, two dogs only in blood samples, and three only in reproductive tract swabs. It is concluded that infection due to Brucella spp. occurs in dogs from the county of Natal, and the detection of DNA of the agent in reproductive tract swabs may be used as complementary tool in the diagnosis of canine brucellosis.
\end{abstract}

Keywords: Brucellosis. Dogs. PCR. Blood. Vaginal swab. Preputial swab.

\section{Introdução}

A brucelose em cães caracteriza-se como doença infectocontagiosa que compromete o sistema reprodutor com alterações que culminam geralmente em infertilidade. É causada por bactérias do gênero Brucella, sendo que os cães podem se infectar por quatro espécies por ordem decrescente de ocorrência: $B$. canis, B. abortus, B. melitensis e B. suis. Nas fêmeas, predominam os abortamentos, natimortos ou nascimento de filhotes fracos, além de orquite e epididimite nos machos. Assume caráter zoonótico em decorrência da constatação de casos em humanos decorrentes, principalmente, do estreito contato com cães (WALLACH et al., 2004; LUCERO et al., 2005).

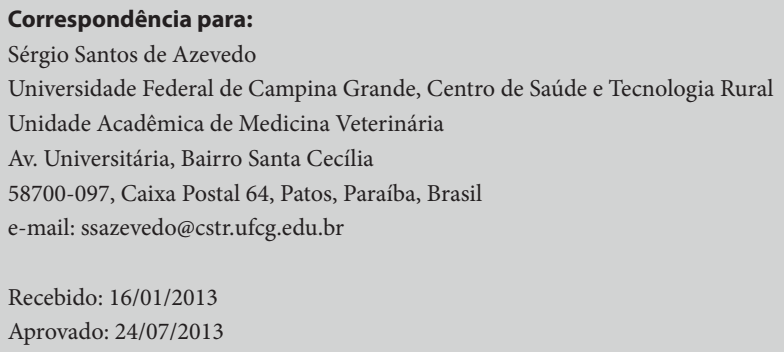


Em função da dificuldade e da baixa especificidade do diagnóstico clínico, a confirmação da brucelose canina deve ser realizada por métodos laboratoriais indiretos e diretos, seja por detecção de anticorpos séricos, isolamento bacteriano ou métodos moleculares (MINHARRO et al., 2005).

O isolamento e identificação de B. canis é um método de alta especificidade diagnóstica, pois demonstra o agente etiológico, mas sua sensibilidade pode ser baixa devido a vários fatores como eliminação intermitente da bactéria, colheita e conservação inadequadas de material, além da utilização de antibióticos previamente à colheita. Além disso, essa prova requer período prolongado de tempo para a identificação do agente e laboratórios de biossegurança de nível 3, o que limita sua implementação (VILLEGAS; NÚÑEZ; PADILLA, 2007).

Dessa maneira, os testes sorológicos, representados pelas provas de soroaglutinação lenta e rápida, e a imunodifusão em gel de agar (IDGA) são os métodos frequentemente utilizados no diagnóstico da doença (HOLLETT, 2006). Esses testes, baseados em antígenos de superfície, apresentam alta sensibilidade, no entanto, os antígenos utilizados também são compartilhados com outros gêneros de bactérias resultando na ocorrência de reações cruzadas (VILLEGAS; NÚÑEZ; PADILLA, 2007).

Os métodos de amplificação de DNA, como a reação em cadeia pela polimerase (PCR), têm demonstrado ser confirmatórios no diagnóstico de brucelose, permitindo encurtar o tempo de diagnóstico, reduzir os riscos de exposição e simplificar os requisitos de infraestrutura necessários (KEID et al., 2009; OLIVERA; GIRALDO; DI-LORENZO, 2011).

Devido à prolongada bacteremia, o sangue é o material de eleição, seja para isolamento do agente ou para detecção do DNA bacteriano. Com o avanço da infecção, essa bacteremia passa a ser intermitente e as brucelas passam a ser encontradas nos órgãos linfoides como medula óssea, baço e fígado, além de órgãos do aparelho reprodutivo como testículo, epidídimo e próstata nos machos, e útero e placenta nas fêmeas (CURRIER et al., 1982).

Estudos empregando o uso de suabes no diagnóstico da brucelose canina são mais recentes, geralmente utilizando animais com alguma suspeita clínica sugestiva de brucelose e provenientes de canis comerciais (KEID et al., 2007; SALGADO et al., 2008). Esse tipo de amostra pode ser útil tanto para isolamento quanto para PCR, entretanto, o isolamento é mais laborioso e demorado, bem como pode ocorrer a presença de contaminantes dificultando o crescimento da bactéria (WANKE, 2004).

Desse modo, devido à escassez de estudos no estado do Rio Grande do Norte, particularmente no município de Natal, à relevância da doença como zoonose e às particularidades nos testes de diagnóstico empregados atualmente para a infecção, objetivou-se com este estudo detectar o DNA de Brucella spp. em amostras de sangue e de suabe do trato reprodutivo em cães sorologicamente positivos para brucelose.

\section{Materiais e Métodos}

De 120 animais soropositivos no teste de Imunodifusão em gel de Agar (IDGA - Kit do Instituto de Tecnologia do Paraná, TECPAR, Curitiba, Paraná, Brasil), provenientes do atendimento de clínicas particulares localizadas do município de Natal, RN, durante o período de março a novembro de 2011, 80 deles foram novamente localizados para colheita de sangue total com anticoagulante (citrato de sódio) juntamente com amostras de suabe do trato reprodutivo (vaginal ou prepucial).

As amostras de sangue foram divididas em alíquotas de $300 \mu \mathrm{l}$, enquanto os suabes foram armazenados em microtubos contendo $1,5 \mathrm{ml}$ de tampão TE (10 mM Tris-HCl pH 8,0, 1 mM EDTA dissódico, pH $8,0)$. Posteriormente, as amostras foram estocadas a $-20^{\circ} \mathrm{C}$ até a realização da PCR.

A extração de DNA das amostras foi feita com o kit comercial DNeasy Blood and Tissue (Qiagen Inc., Turnberry Lane, Valencia, USA). Para as amostras 
de sangue, a extração foi feita a partir das alíquotas formadas, e para as amostras de suabe, este foi retirado e o tubo foi centrifugado a $14000 \mathrm{rpm} / 2 \mathrm{~min}$, com posterior descarte do sobrenadante. O pellet foi ressuspendido em $180 \mu \mathrm{l}$ de tampão ATL (disponível no kit), e o protocolo de extração foi seguido (no kit para sêmen, sangue total e leite) sem adição de PBS. O DNA obtido foi armazenado a $-20^{\circ} \mathrm{C}$ até o momento da amplificação. Para a reação foram utilizados os primers ITS66 e ITS279 (KEID et al., 2007), os quais amplificam uma sequência de $214 \mathrm{pb}$, específicos para bactérias do gênero Brucella.

A amplificação das amostras de DNA foi realizada em microtubos de $200 \mu \mathrm{l}$ com volume final de $12,5 \mu \mathrm{l}$ em que foi utilizado $0,5 \mu \mathrm{M}$ de cada primer e uma solução pré-misturada contendo $200 \mu \mathrm{M}$ dNTP, 1,5 mM MgCl2, 5U Taq DNA polymerase (Taq PCR Master Mix - QIAGEN/USA) e 2,5 $\mu$ L DNA. No ciclo empregado, inicialmente, as amostras foram submetidas a uma desnaturação de $95^{\circ} \mathrm{C}$ por 2 minutos e a seguir empregados 40 ciclos de amplificação divididos em quatro fases: desnaturação $-95^{\circ} \mathrm{C} / 30$ segundos; anelamento $-62^{\circ} \mathrm{C} / 30$ segundos; extensão $-72^{\circ} \mathrm{C} / 30$ segundos; e extensão final $-72^{\circ} \mathrm{C} / 5$ minutos (KEID et al., 2007).

A análise do produto amplificado foi realizada por eletroforese em gel de agarose a 2,0\% com tampão de corrida TBE 0,5 X (0,045M TRIS-Borato e $1 \mathrm{nM}$ de EDTA, $\mathrm{pH} 8,0$ ) e o gel submetido à voltagem constante de 6-7 V/cm. O padrão de peso molecular empregado foi de $100 \mathrm{pb}$ (Thermo Fisher Scientific Inc. Fermentas, Vilnius, Lituânia). As amostras para o gel foram coradas com Blue Green (LGC Biotecnologia, Cotia, São Paulo, Brasil) e, posteriormente, fotografadas sob luz ultravioleta pelo sistema de fotodocumentação.

Para a comparação das frequências de amplificações positivas de DNA nos animais, considerando somente as amostras de sangue, bem como as amostras de suabes do trato reprodutivo juntamente com as amostras de sangue, foi utilizado o teste Binomial com nível de significância de $5 \%$.

\section{Resultados e Discussão}

Dos 80 cães avaliados, em seis $(7,5 \%)$ ocorreu amplificação de DNA de Brucella spp., sendo que um animal foi positivo nos dois tipos de amostras (sangue e suabe vaginal), dois animais com amostras de sangue e três com amostras de suabe do trato reprodutivo (Figura 1). Duas cadelas foram positivas no suabe vaginal e dois machos em suabe prepucial (Quadro 1).

Nota-se que com a utilização das amostras de suabe do trato reprodutivo, a frequência de amplificações positivas de DNA passou de 3,7\% (3/80), utilizandose apenas amostras de sangue, para 7,5\% (6/80), no entanto, não foi observada diferença significativa $(\mathrm{p}=0,071)$. Essa diferença entre as amostras na detecção molecular do agente, embora não identificada estatisticamente, pode ser explicada pelo fato de a bacteremia na brucelose canina, apesar de prolongada, passar a ser intermitente e eventualmente diminuir em infecções crônicas, de modo que o agente passa a ser recuperado a partir de outros sítios de infecção (FERNANDES et al., 2011).

Embora fetos e placentas de fêmeas que abortaram constituam excelente material por conter grande carga de bactérias, assim como secreções vaginais provenientes de cadelas que abortaram e de cadelas em estro (CICUTA; MIRANDA, 1990; CARMICHAEL; GREENE, 1998), foi encontrado o DNA do agente nas amostras de suabe vaginal provenientes de cadelas que não se encontravam em nenhuma destas condições. Essa eliminação vaginal pode ocorrer em períodos variáveis nas fêmeas não gestantes e que não se apresentam em estro (KEID et al., 2007).

Keid et al. (2007) também obtiveram bons resultados com o emprego da PCR de suabe vaginal como forma suplementar para o diagnóstico da brucelose canina. Verificou-se que a PCR foi um bom teste confirmatório para o diagnóstico de brucelose em fêmeas suspeitas de infecção, especialmente as negativas para cultura de sangue ou PCR de sangue, fato este também constatado no presente estudo em relação aos resultados da PCR. 


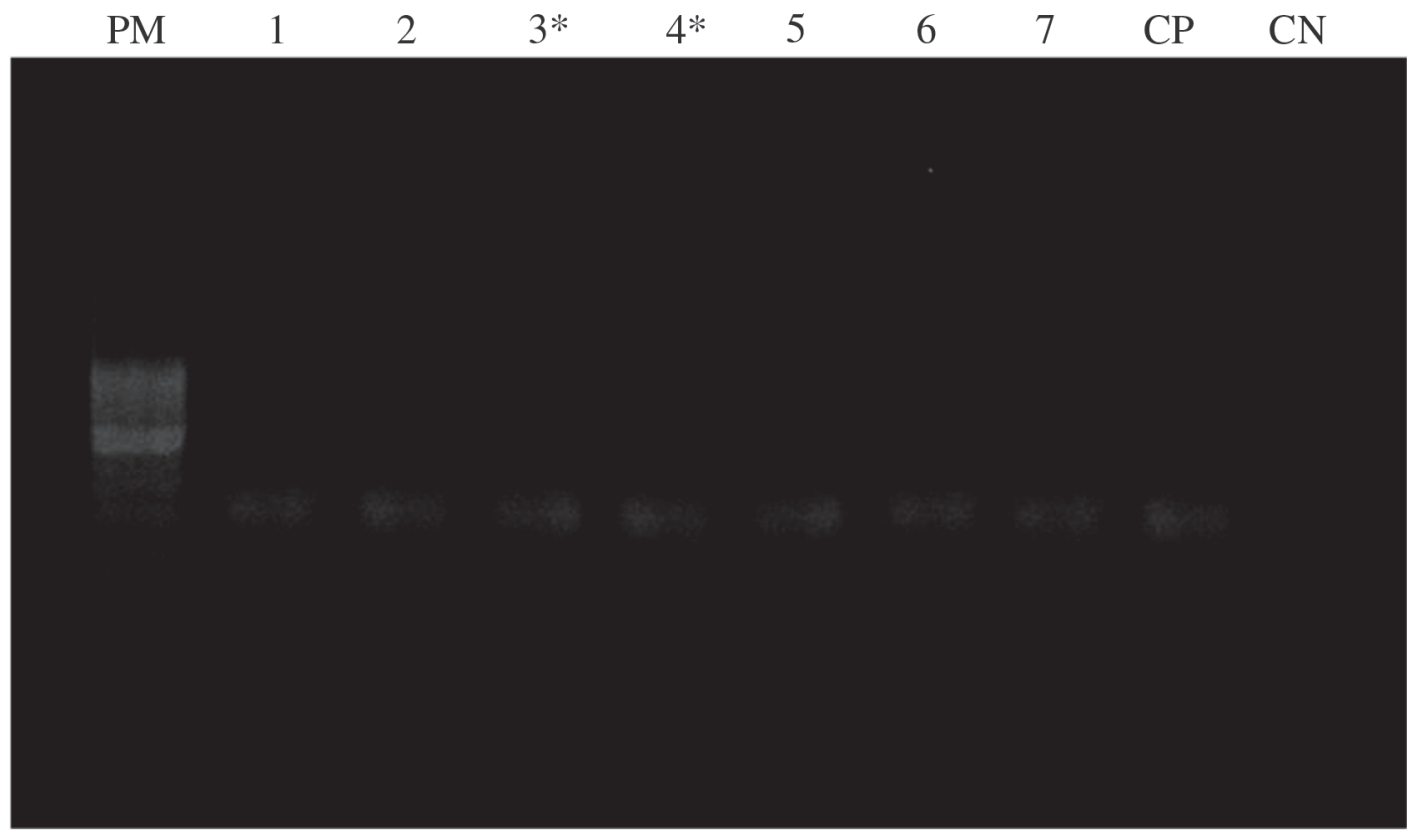

Figura 1 - Eletroforese em gel de agarose 2\%. PM: marcador de peso molecular 100 pb (Fermentas); Linhas 1, 2 e 3: amostras de sangue total; Linhas 4 e 5: amostras de suabe vaginal; 6 e 7: amostras de suabe prepucial. CP: controle positivo B. ovis; $\mathrm{CN}$ : controle negativo. * Amostras pertencentes a um mesmo animal Fonte: arquivo pessoal.

Quadro 1 - Quantidade de amplificações positivas para Brucella spp. de 80 cães sororreagentes no IDGA, provenientes de clínicas particulares do município de Natal - RN

\begin{tabular}{|c|c|c|c|}
\hline Identificação do animal & PCR de sangue & PCR de suabe vaginal & PCR suabe de prepucial \\
\hline 1 & $\mathrm{X}$ & $\mathrm{X}$ & \\
\hline 2 & $\mathrm{X}$ & & \\
\hline 3 & $\mathrm{X}$ & & \\
\hline 4 & & $\mathrm{X}$ & \\
\hline 5 & & & $\mathrm{X}$ \\
\hline 6 & & & $\mathrm{X}$ \\
\hline
\end{tabular}

Fonte: arquivo pessoal.

Nos machos, com o aparecimento de amostras positivas apenas no suabe prepucial, pode-se inferir que estes animais se encontravam em estágio crônico da infecção (CARMICHAEL; GREENE, 1998). A amplificação de DNA do agente em amostras de suabes de prepúcio sugere que este fato seja decorrente da contaminação do prepúcio com o agente presente na urina ou líquido seminal (MINHARRO et al., 2005).
Salgado et al. (2008) amplificaram DNA de Brucella spp. em cinco $(22,7 \%)$ de 22 amostras de suabe prepucial, enquanto no presente estudo essa frequência foi de $6,2 \%(2 / 32)$. Vale ressaltar que, naquele estudo, foram utilizados animais de canis em São Paulo com pelo menos um sinal clínico indicativo da doença, enquanto no presente estudo foram utilizados cães sem qualquer sinal clínico sugestivo, o que poderia justificar essa diferença nas frequências de amplificação. 
Dessa maneira, pode-se inferir que a utilização de suabes vaginal e prepucial para detecção de DNA de Brucella spp. em cães pode ser uma alternativa no diagnóstico confirmatório da infecção, uma vez que, diferente de punção de fígado, baço ou obtenção de medula óssea, uma colheita de sangue e de suabe constituem formas de obtenção de amostras minimamente invasivas aos animais. Reforça-se, também, a associação dos métodos laboratoriais diretos e indiretos para o diagnóstico da infecção.

\section{Referências}

CARMICHAEL, L. E.; GREENE, C. E. Canine brucellosis. In: GREENE, C. E. Infectious diseases of the dog and cat. 2. ed. Philadelphia: W.B. Saunders, 1998. p. 248-257.

CICUTA, M. E.; MIRANDA, A. O. Primer aislamiento de Brucella canis en la ciudad de Corrientes, Argentina. Veterinaria Argentina, v. 7, n. 67, p. 463-465, 1990. Disponível em: <http://www. veterinariargentina.com/revista/>. Acesso em: 15 jul. 2012.

CURRIER, R. W.; RAITHEL, W. F.; MARTIN, R. J.; POTTER, M. E. Canine brucellosis. Journal of American Veterinary Medical Association, v. 180, n. 2, p. 132-133, 1982.

FERNANDES, A. R. F.; AZEVEDO, S. S.; PIATTI, R. M.; PINHEIRO, E. S.; GENOVEZ, M. E.; AZEVEDO, A. S.; BATISTA, C. S. A.; ALVES, C. J. Brucella canis infection in dogs attended in veterinary clinics from Patos, Paraíba State, Brazil. Brazilian Journal of Microbiology, v. 42, n. 4, p. 1405-1408, 2011. Disponível em: <http://www.scielo.br/pdf/bjm/v42n4/v42n4a23. pdf $>$. Acesso em: 6 jun. 2011.

HOLLETT, R. B. Canine brucellosis: outbreaks and compliance. Theriogenology, v. 66, n. 3, p. 575-587, 2006. Disponível em: <http://www.sciencedirect.com/science/article/pii/S0093691 X06002305>. Acesso em: 22 nov. 2012.

KEID, L. B.; SOARES, R. M.; VASCONCELLOS, A. S. A.; CHIEBAO, D. P.; SALGADO, V. R.; MEGID, J.; RICHTZENHAIN, L. J. A polymerase chain reaction for detection of Brucella canis in vaginal swabs of naturally infected bitches. Theriogenology, v. 68 , n. 9, p. 1260-1270, 2007. Disponível em: <http://www. theriojournal.com/article/S0093-691X\%2807\%2900529-8/ abstract>. Acesso em: 7 jun. 2012.

KEID, L. B.; SOARES, R. M.; VASCONCELLOS, S. A.; MEGID, J.; SALGADO, V. R.; RICHTZENHAIN, L. J. Comparison of agar gel immunodiffusion test, rapid slide agglutination test, microbiological culture and PCR for the diagnosis of canine brucellosis. Research in Veterinary Science, v. 86, n. 1, p. 2226, 2009. Disponível em: <http://www.sciencedirect.com/science/ article/pii/S0034528808001161>. Acesso em: 20 jun. 2012.

LUCERO, N. E.; ESCOBAR, G. I.; AYALA, S. M.; JACOB, N. O. Diagnosis of human brucellosis caused by Brucella canis. Journal

\section{Conclusões}

Os resultados apresentados indicam que a infecção por Brucella spp. estava presente em cães atendidos em clínicas veterinárias do município de Natal, uma vez que a presença do agente foi detectada em amostras de sangue e suabe vaginal e prepucial, bem como sugere-se que a detecção de DNA do agente em amostras de suabes do trato reprodutivo pode ser utilizada como ferramenta suplementar no diagnóstico de brucelose canina.

of Medical Microbiology, v. 54, n. 5, p. 457-461, 2005. Disponível em: <http://jmm.sgmjournals.org/content/54/5.toc >. Acesso em: 20 out. 2012 .

MINHARRO, S.; COTTORELlO, A. C. P.; MIRANDA, K. L.; STYNEN, A. P. R.; ALVES, T. M.; LAGE, A. P. Diagnóstico da brucelose canina: dificuldades e estratégias. Revista Brasileira de Reprodução Animal, v. 29, n. 3/4, p. 167-173, 2005. Disponível em: <http://www.cbra.org.br/portal/publicacoes/rbra/2005/ rbrajd2005.html $>$. Acesso em: 5 set. 2012.

OLIVERA, M.; GIRALDO, C. A.; DI-LORENZO, C. Identificación por PCR de Brucella canis en sangre y leche canina. Reporte de un caso. Archivos de Medicina Veterinaria, v. 43, n. 3, p. 295-298, 2011. Disponível em: <http://www.scielo.cl/scielo.php ?pid=S0301732X2011000300012 >. Acesso em: 25 out. 2012.

SALGADO, V. R.; KEID, L. B.; LIRA, N. C.; NOZAKI, C. N.; CORTEZ, A.; RICHTZENHAIN, L. J.; VASCONCELLOS, S. A.; MEGID, J. Evaluation of rapid slide agglutination test with and without 2-mercaptoetanol (2ME-RSAT and RSAT) and comparison with microbiological culture and Polimerase Chain Reaction (PCR) for the diagnosis of canine brucellosis. $\mathbf{O}$ Biológico, v. 70, n. 2, p. 107-216, 2008. Disponível em: <http:// www.biologico.sp.gov.br/rev_bio.php?vol=70\&num $=2>$. Acesso em: 22 ago. 2012.

VILLEGAS, H. H. L.; NÚÑEZ, N. V. A.; PADILLA, C. R. Laboratorios de bioseguridad nivel 3 y 4: investigación de patógenos peligrosos. Revista Mexicana de Patologia Clínica, v. 54, n. 4, p. 177-186, 2007. Disponível em: <http://www.medigraphic.com>. Acesso em: 15 out. 2012.

WALLACH, J. C.; GIAMBARTOLOMEI, G. H.; BALDI, P. C.; FOSSATI, C. A. Human infection with M-strain of Brucella canis. Emerging Infectious Diseases, v. 10, n. 1, p. 146-148, 2004. Disponível em: <http://wwwnc.cdc.gov/eid/article/10/1/pdfs/ 02-0622.pdf >. Acesso em: 15 dez. 2012.

WANKE, M. M. Canine brucellosis. Animal Reproduction Science, v. 82/83, p. 195-207, 2004. Disponível em: <http://www. sciencedirect.com/science/journal/03784320/82-83>. Acesso em: 14 set. 2012. 